\title{
A descoberta dos vínculos sociais. Os fundamentos da solidariedade
}

\author{
Luiz Inácio Germany Gaiger \\ Ediciones Unisinos, 2016, Sao Leopoldo, \\ Rio Grande do Sul, Brasil 251 p.
}

\author{
Nicolás Gómez Núñez \\ Universidad Central de Chile, Santiago, Chile \\ Email: nicolas.gomez@ucentral.cl
}

El descubrimiento de los vínculos sociales, como se titula la obra que comento, muestra una interpretación que se inicia poniendo en cuestión las razones prácticas del utilitarismo y continúa sistematizando los axiomas sobre la reciprocidad que se tienen hasta 2016. Luiz Ignacio Gaiger, sociólogo brasileño autor del escrito, dispone ese recorrido en seis capítulos y una bibliografía, la cual tendrá comentarios al final de esta reseña, y cierra incorporando la eficiencia sistémica del ayllu, se puede decir al retomar su propuesta anterior (Gaiger, 2004); y las racionalidades de la autogestión, parafraseando su trabajo de 2006.

Antes de iniciar el repaso por las tres dimensiones centrales de la obra, supongo que las conjeturas de Gaiger están atadas a su experiencia en el Grupo de Investigación en Economía Solidaria y Cooperativa de la Universidad del Vale del Río dos Sinos (Gaiger y EcoSol, 2014), el cual cooperó en los censos de Economía Solidaria de Brasil, y es de esperar que halla influido su participación en la revista Otra Economía, que difundía los estudios en economías no utilitarias. Es indiscutible que también hay un escenario más amplio, un clima de época se podría decir, que envolvió a estas organizaciones en un circuito de ciencia y tecnología nacional y latinoamericano.

Este circuito se articula en estados de emergencia derivados de las dictaduras, la pobreza, la exclusión o el hambre. Ocurrió entre 1976 y 1990, esa vez las organizaciones de trabajo y solidaridad y la perspectiva de Economía Solidaria, fueron la punta del iceberg. Recientemente han sido las políticas públicas de Economía Solidaria, eso se puede cotejar, siguiendo a Coraggio (2003), en Venezuela (desde 1998), Argentina (desde 2003), Ecuador (desde 2006), Bolivia (desde la "guerra" del agua de 2000) y en Brasil desde 2003, cuando los planteamientos del Foro Brasileño de Economía Solidaria fueron incorporados en los ministerios, incluso con programas basados en la participación popular como ocurrió en las Conferencias de Economía Solidaria (CONAES). 
En todos estos procesos de recreación de las políticas públicas desde abajo, se observa que la categoría de Economía Solidaria se incorporó por la concurrencia de los movimientos sociales que empalmaron con los recursos del Estado, los pueblos originarios impusieron su visión de economía comunitaria indígena y Buen Vivir a través de mecanismos democráticos y los actores políticos y agentes económicos del capitalismo de mercado, irrumpieron para detener la legitimación de las economías comunitarias, estatales, privadas y social cooperativa, en los sistemas jurídicos y político-administrativos.

Entrando al contenido que nos convoca. El primer aspecto del libro es la evaluación de la capacidad explicativa que tiene la conducta egoísta en las relaciones de cooperación. Asunto ineludible al estudiar economías y que exige una posición para salir del atolladero. Gaiger opta por el recorrido largo al volver al "solipsismo económico" diría Polanyi (2009, p. 70). Pudo elegir la estrategia de Samuelson (1968, p. 104), es decir: olvidar la historia y sostener que es el individuo autónomo, creativo y calculador de riesgos el que tira el carro de la producción.

Obsérvese que si bien Gaiger es un intelectual crítico del utilitarismo, él demuestra pulcritud cuando trata las ideas que fundamentan el derecho natural ofrecido por Bentam. Es más, dicho recorrido enseña el origen de su consecuencia lógica al explicar porqué las matemáticas son esenciales en una versión de la ciencia del comportamiento humano que se basa en hechos inmediatamente observables, traducibles a números y que prescinde de las variables que se expresan cuando transcurre un complejo de interacciones. Por tanto, Gaiger no da tiros a la bandada, al contrario, sus agudos comentarios ponen en tensión la autonomía individual en la envergadura de las interdependencias y reconoce los sesgos que promueve el individualismo metódico en la construcción de las teorías sociales.

Este ámbito de los argumentos concluye con el contraste entre el don y la cooperación basada en el agente egoísta. Antes de llegar a este punto, el o la lectora habrá pasado por cinco figuras que resumen lo que el autor quiere que retengamos, esta didáctica será una característica de la pedagogía del libro. El contrapunto teórico finaliza cuando Gaiger invita a Godbout, y juntos sostienen que la inversión en confianza es una estrategia que impide la guerra y consolida un endeudamiento positivo perpetuo (Gaiger, 2016, p. 75).

El segundo aspecto de los argumentos del libro son respuestas a la siguiente pregunta, ¿cómo otros principios distintos a los del intercambio utilitario pueden ganar peso y supremacía? (Gaiger, 2016, p. 138). A mi entender, el autor se obliga a evaluar la ubicación que tiene la reciprocidad en la vida cotidiana y en una teoría sobre las economías. En ambos planos se repite una práctica: criar alianzas. En la vida cotidiana sería una práctica eficiente que construye comunidad al jugar a favor de los intereses de las otras personas, comunidades u organizaciones. A nivel de la teoría social, sería un mandato cultural que dispone a los involucrados para ser goberna- 
dos por el compromiso de: dar, aceptar y devolver. Entonces Gaiger, apoyado ahora en los estudios de Caillé, nos propone la existencia de un "homo donator" (Gaiger, 2016, p. 83), que marcar el sesgo que ha impuesto la acepción del homo oeconomicus al llevarnos a concebir la economía al margen de la solidaridad.

A favor de la propuesta del homo donator, el sociólogo brasileño describe la comensalidad, la autarquía y el mercado de reciprocidad. La primera es observada desde los estudios de Razeto, ahí Gaiger reconoce que es una expresión de la identidad grupal, la memoria colectiva, de una noción de justicia y equidad, factor de incorporación de nuevos integrantes a la comunidad y de la subordinación de las estrategias económicas a los ciclos de la reproducción familiar. Por su parte, la autarquía es tratada como una consecuencia de la "domesticidade" (Gaiger, 2016, p. 98), es decir, la gestión del autoconsumo que caracterizaría a la economía familiar campesina y a la economía popular. Y el tratamiento del mercado de reciprocidad es concebido como integración reglamentada que facilita la circulación de objetos y asistencias (Gaiger, 2016, p. 109).

$\mathrm{Al}$ cierre de este punto debo subrayar que Gaiger no pierde de vista la consecuencia de la asimetría que fija la reciprocidad cuando es parte del utilitarismo. Por lo cual, recorre la topografía de la avanzada colonizadora de la empresa con fines de lucro sobre el territorio de la "domesticidade". El repaso enuncia los dispositivos de la política neoliberal: filantropía, responsabilidad social, empresas sociales o negocios inclusivos, que pretenden construir situaciones donde la ciudadanía es acorralada en la jaula del consumidor fiel, mientras los derechos de los trabajadores caen en el olvido por la fuerza de las dádivas que cae en cascada, siempre de arriba a bajo, pacificando la conciencia de clase, reduciendo la expectativa de las reivindicaciones y robusteciendo la desigualdad distributiva que beneficia a una plutocracia (Gaiger, 2016, p. 126-129)

A modo de crítica. Gaiger debió seguir los pasos de Braudel (2002) para reconocer dos tipos de capitalismo: uno transparente y próximo y otro con información clasificada y privatizada y donde el intermediario, corredor libre hedonista, se beneficia. Y lo relevante, habría ofrecido una opinión sobre el papel de la reciprocidad cuando es la adaptación del segundo capitalismo a los modos de producción y distribución del primero.

Usando esta hipótesis se puede incluir la reciprocidad negativa presentada por Sahlins (1963) y trabajada por Lomnitz desde la asimetría: “este acto inicial tiene la intención de forzar a su víctima a involucrarse en un ciclo positivo de intercambios con su perpetrador (...) comienza con un robo, una violación, una intimidación o un homicidio (...) la intimidación es seguida por un don simbólico que representa la deuda de la parte subordinada" (Lomnitz 2005, p. 322). Así explicaríamos en parte la privatización de los bienes comunes que se inició con el terrorismo de Estado en el último cuarto del siglo pasado bajo las recomendaciones de profesor Milton Friedman, como ha sucedido en Chile por ejemplo. 
Desde esta perspectiva y dados los hechos políticos en Brasil a partir de 2017, Luiz Ignacio Gaiger debería incorporar las autodependenciasinterclase jerarquizadas que organizan una tecnología social de burocracia-tecnocracia-clientelismo partidario. Porque amplía la mirada sobre las economías locales al introducir las redes egocentradas que articulan un tejido múltiple, complejo y con alto grado de cierre, y donde el campesino con capital social y el político caudillo, cacique, broker o gestor, son claves (Durston, 2005).

El tercer aspecto de los argumentos del libro, arranca con la recuperación de la categoría de “lazos funcionales” de Bajoit (Gaiger, 2016, p. 113). Esta noción nombra la integración gracias al sentimiento de deber de los individuos cuando realizan sus prácticas en búsqueda de un objetivo común, o: trabajo y civismo. A esta altura de la lectura quedará claro que la solidaridad orgánica de Durkheim es el telón de fondo, por lo cual, los lazos funcionales son puentes entre la conducta individual y la matriz de interpretación o el patrón de integración. Desde aquí se tratan casos contemporáneos como los creadores de software libre por ejemplo, donde la coherencia de su funcionamiento pasa por la identidad de las comunidades virtuales. Entonces Gaiger dialoga con Tönnies, y vislumbra que la eficiencia de la comunidad prescinde de los encuentros cara a cara y se apoya en la coordinación de funciones finitas y trascendentes (Gaiger, 2016, p. 103, p. 137).

Para finalizar la reseña dedicaré dos comentarios a la bibliografía del libro. El primero se refiere a la posibilidad de leer diálogos entre investigadores en escenarios y encuentros que se presentan como si hubiesen acontecido. A modo de ejemplo, el virtual encuentro de Laville, Caillé y Razeto o la conversación entre Mauss, Polanyi y Bentham, Sen. El segundo comentario busca animar a los que se introducen en los estudios de las economías para que repasen los títulos de las obras apuntadas. A mi modo de ver, el sociólogo brasileño actúo como un curador de obras de arte y seleccionó las que son fundamentales porque develan partes del objeto de estudio, desarrollan preguntas que se mantienen sin respuesta o muestran metodologías de trabajo que documentan los fenómenos sociales. 


\section{Bibliografía}

Braudel, F. (2002.) La dinámica del capitalismo. México D.F., México: Fondo de Cultura Económica.

Coraggio, J. (2013). La Presencia de la Economía Social y Solidaria (ESS) y su Institucionalización en América Latina, 2013. Santiago, Chile: CEPAL

Durston, J. (2005). ¿Apitutados o apechugadores? El clientelismo político en el campo chileno. En Porras, J. y V. Espinoza (compiladores). Redes: enfoques y aplicaciones del análisis de redes sociales. Santiago, Chile: Universidad Bolivariana.

Gaiger, L., y Grupo Ecosol. (2014).A EconomiaSolidária no Brasil. Sân Leopoldo, Brasil: OIKOS.

- (2006). A racionalidade dos formatos productivos autogestionários, SeE, 21, 513-545.

. (2004). Eficiencia sistémica. En David, A., (Org.), La otra economía.Buenos Aires, Argentina: Universidad Nacional General Sarmiento, Fundación OSDE, Altamira.

Lomnitz, C. (2005). Sobre reciprocidad negativa, Revista de Antropología Social, (14) 311-339.

Polanyi, K (2009)El sustento del hombre. Madrid, España: Capitán Swing.

Samuelson, P. (1968). Curso de Economía Moderna. Una descripción analítica de la realidad económica. Madrid, España: Aguilar.

Sahlins, M. (1963). Poor Man, RichMan, Big Man, Chief: PoliticalTypes in Melanesia and Polynesia. ComparativeStudies in Society and History, (5) 285-303. 